"This is the peer reviewed version of the following article: [Untangling the knot: The information practices of enthusiast car restorers | Lloyd,

Annemaree; https://researchoutputs.uts.edu.au/userprofile.html?uid=2206 | Journal of the Association for Information Science and Technology | Article number asi.24284 | Online publication date 23 Jul 2019 | Publisher Wiley

], which has been published in final form at [https://onlinelibrary.wiley.com/doi/abs/10.1002/asi.24284] This article may be used for non-commercial purposes in accordance with Wiley Terms and Conditions for SelfArchiving 


\title{
Untangling the knot: The Information Practices of Enthusiast Car Restorers
}

\author{
Annemaree Lloyd \\ University College London. Annemaree.lloyd@ucl.ac.uk \\ Michael Olsson \\ University of Technology Sydney, Australia. Michael.Olsson@uts.edu.au
}

\section{Abstract}

A study of enthusiast car restorers is used to illustrate how an information practice approach can provide information science researchers with a richer, more nuanced understanding of the complex inter-relationship between people, technology and information. An ethnographic approach incorporating both semi-structured interviews and in the garage ethnographic observation was employed. Analysis was undertaken using an inductive, thematic approach. The findings demonstrate that participants' information environments are rich and complex. Participants' accounts emphasised the corporeal and embodied nature of the restoration process, and this may account for why they privileged the social networks they had developed, often over many decades, over online resources and communities. The findings indicate that participants are engaged in much more than applied problem solving. What is also evident is that engagement in the social world of car restoration, and the networks of social knowledge sharing it affords, is significant for the emotional support it provides for older men who often lose these networks later in life. In a sense, the participants are not only rebuilding their cars but also their own sense of self

\section{Introduction}

This article examines the study of the information practices of enthusiast car restorers. It will highlight the central role of embodied information practices (Olsson \& Lloyd, 2017) for participants' restoration work. The study's findings demonstrate that such embodied practices are not individual or idiosyncratic but social constructs, whose importance is recognised and valued within the restoration community.

In recent years a small but growing number of information researchers have studied leisurebased communities (e.g. Case, 2009; Fulton, 2009; Hartel, 2006), including one study in a motorsport context (Joseph, 2016). The overwhelming majority of such studies locate themselves within the information behaviour umbrella discourse (Savolainen, 2007), which a range of critics (e.g. Talja et. al, 2005; Talja \& Hansen, 2005; Lloyd, 2007; Olsson, 2009) argue continues to be dominated by approaches focusing on the purposive behaviour of individual information seekers. The present study adopts a very different theoretical and methodological approach grounded in the information practices discourse (Savolainen, 2007).

Studies of leisure by information researchers, as in a range of other fields (e.g. (Heley \& Jones, 2013; Hickman et. al, 2017), largely rely on sociologist, Robert Stebbins' work on serious leisure when seeking to define the nature of leisure. Stebbins work has become 
familiar to many in LIS through its use by Hartel (2006) in her study of gourmet cooking. Stebbins defines serious leisure as the:
...systematic pursuit of an amateur, hobbyist, or volunteer core activity that people find so substantial, interesting, and fulfilling that, in the typical case, they launch themselves on a (leisure) career centered on acquiring and expressing its special skills, knowledge, and experience. $(2007,5)$

Whilst the present study's approach is broadly in agreement with Stebbins' definition, our own previous research which has focused embodied knowledge and ways of knowing (Lloyd, 2009, 2014; Olsson, 2010, 2016) suggests that the serious leisure approach alone does not provide sufficient theoretical tools to allow an in-depth understanding of how enthusiasts become connected to others, access expertise that is built up over time and in turn become embodied in their hobby or leisure pursuit.

The relationship between leisure studies and the embodied experience is highlighted by Cox et. al, (2017) in their review of existing information studies:
A focus on written sources reflects the origins of information studies in the provision of information through libraries and digital repositories. Yet activities involving the body - embodied activities - are very important in serious leisure... This is most obvious in sports, where the central activity is carried out with the body and experienced through the senses. But it equally applies to ... crafts and collecting, which revolve around material objects being produced and organised. Indeed, the centrality of embodied experience to all aspects of human life makes the relative neglect of the body in information behaviour studies surprising and potentially problematic. $(2017,386-7)$

In the present study, information practices are viewed as being shaped and maintained in the context of people's actions and interactions with other people, materials, signs, symbols and tools which are all constituent elements responsible for the formation of information environments and information landscapes. This view of information practice represents 'a more sociologically and contextually oriented line of research" (Talja, 2005, p.123) and an emphasis is placed on the intersubjective and discursive nature of interaction and knowledge production (Talja, 2005). Where this approach has been adopted in information science research (Sundin and Johannison 2005, McKenzie, 2003; Talja, 2005; Talja and Hansen, $2005)$ there is an emphasis placed on "social practices, the concrete and situated activities of interacting people, reproduced in routine social contexts across time and space" (Savolainen, 2007, p. 122). We extend this understanding of information practice to emphasise the body as a site of embodied knowledge which is central to information practice, acting as a site where social and epistemic information intersect. A theme of this research is the role of the body in shaping people's information practices and their relationship with technologies, both old and new.

At the same time, the study's findings will also demonstrate that there are contexts and communities, where the importance of hands-on knowledge renders even multi-media information resources lacking as information sources for community members. In addition, 
the study highlights that in the right, skilled hands, objects not generally thought of as 'informative' (hand tools, car parts) can become information sources in their own right.

The restoration stories of car enthusiasts were analysed in an ongoing project on embodied knowledge and ways of knowing (Olsson \& Lloyd, 2017). From these stories we identify, analyse and discuss how technology is implicated in restoration practice, and the opportunities it offers to the predominately male participants of this study. Two areas are highlighted from the larger study for discussion: firstly, the functional role of technology in terms of the restoration; and secondly the opportunities for men (often retired) to develop ambient relationships and co-presence, and a sense of solidarity with other men who share the same love, passion and commitment for their restoration projects. We link the project of restoration to literature on practice, information practice, and embodiment theory, and situate this lens through the practice of restoration and geographies of enthusiasm.

We also consider questions about the capture of embodied and social knowledges and ways of knowing - questions that are increasing becoming silenced, relegated, and lost in the technologically driven discursive practice of the accelerated age

\section{Literature Review}

\section{Restoration, and practice}

Restoration provides the context for this study and is defined as "a debt paid forward to the future by accurately interpreting its past" (DeLyser \& Greenstein, 2017, p. 1466) and while there is an abundance of literature devoted to the applied elements of restoration projects, little has been written about restoration as a specific form of practice, or the object of restoration as a specific type of project. As DeLyser \& Greenstein observe, to engage with the practice of a restoration project, enthusiasts must link and map historical knowledge, and an understanding of aesthetics with technical, mechanical knowledge and skills (p. 1464). To this list we would also add embodied knowledges.

Whilst studying restoration on one level has much in common with studies of repair (Jackson, 2014, Houston, 2017), differences exist which shape the analytical contours of the present study. Repair refers to the act of making something functional again (i.e. fixing a problem), whereas restoration, as the study's findings, as described below, demonstrate, references a more complex act of reconstructing an object where the restorer can choose between a range of competing discourses around the 'correct' way to restore their car.

In contrast to the idea of repair, the variations in the restoration discourse represent a social geography, linking enthusiasts to the discourse restoration environment and the multitude of information landscapes that reference it (Lloyd, 2017). Like other practices of making and remaking, restoration requires enthusiasts to engage corporeally and iteratively and to develop information practices that reference the site and link them to forms of embodied knowledge and expertise that may only be available at-the-moment of practice (Bonner and Lloyd 2011). Successful restoration practice is predicated on wide and often deep social networks that are built up over time or inherited. In this respect, 'knowing a bloke who knows a bloke' may accurately sum up a central theme in the car enthusiast's modus operandi, but at a deeper level it can reveal that knowledge ties amongst this group of enthusiasts are knotted in a rich and complex structure, often spanning generations. This suggests spatial and temporal elements that may be explored in future work on restoration practice. 
Practice theory shapes the theoretical approach of this study. In general, a practice perspective acknowledges the nexus of practices (Schatzki, 2002) as the central feature of everyday life.

Practice theory has been cited and employed as a theoretical frame by a number of authors in the Library and Information Science field (e.g. Savolainen, 2008, Lloyd, 2010, Olsson, 2016, Pilerot, 2013; Cox 2017). These works draw from first-wave interests (Bourdieu, 1977, Giddens, 1984) and second-wave which feature both ontological approaches (Schatzki, 2002; Kemmis and Grootenboer 2008; Reckwitz 2000) and epistemological approaches (Feldman and Orlikowski, 2011, Gherardi 2008, 2009, Lave and Wenger 1991, Nicolini, 2012). While each theory of practice emphasizes different elements, features common among all of them allow us to describe practices as composed of social and corporeal elements. From this perspective, Nicolini argues that:

The social world appears as vast array or assemblage of performances made durable by being inscribed in skills human bodies and minds, objects and texts and knotted together in such a way that the results of one performance become the resource of another. $(2012$, p.2)

Practice theory is grounded in a general understanding that knowledge represents mastery which is articulated and expressed in the ability to carry out a performance and share the accumulated benefits of experience with others. As Nicolini $(2012$, p.5) suggests

Becoming part of an existing practice ... involves learning how to act, how to speak (and what to say), but also how to feel, what to expect and what things mean.

While there is no uniform view of practice (Niciolini, 2012), there are common themes (with varying emphasis) acknowledge by practice researchers (including those in LIS) that direct researchers' attentions. To summarise, practices:

- Are constituted temporally, spatially, and materially and reference the textures of everyday life (Reckwitz, 2002)

- Are situated, social and relational (Schatzki, 2002)

- Are composed by bodies which inscribe the discursiveness and routine of social order and material things across all social affairs (Nicolini 2012; Reckwitz 2002; Orlikowski and Scott, 2015)

- Consist of organised constellations or patterns of activity and understandings that are critical to the shaping and process of human life (Schatzki 2012, p.14)

- Contain propositional and non-propositional elements - e.g. articulated through intelligibly via text but also articulated and expressed in non-textual forms of practical knowledge through the body and artefacts which are named via the practice. (Mahon, Kemmis, Francesco, Lloyd, 2017)

- Reject dualisms e.g. mind/body, agency/structure (Bourdieu and Wacquant, 1992; Feldman \& Orlkowski, 2011); and,

- Acknowledge the importance of materiality and materials, communications, text/symbols in the constitution of practice (Orlikowski \& Scott, 2015; Mahon, Kemmis, Francesco, Lloyd, 2017) 


\section{Embodied Information practices}

The concept of embodiment is also central to a conceptualisation of practice and is explored across numerous disciplines and fields. In Library and Information Science, it has relevance to research related to information literacy and ways of knowing (Lloyd 2017), information practices (Gorichanaz, 2015; Lindh 2018; Lloyd, 2007; Olsson 2016, Veinot, 2007), information behaviour (Leug, 2014) and human computer interaction (Dourish, 2001). A recent special edition of the Journal of Documentation (Cox; Griffin \& Hartel, 2018) has highlighted the centrality of the embodied experience and questioned why this aspect of information research has been neglected, echoing Lloyd's 2009 claim that insufficient attention is paid to the body which exists as an absent presence in our current theorising about the information experience (Lloyd, 2014; Shilling; 2012)

In her work with professional firefighters, ambulance officers and nurses, Lloyd, (2004; 2009; Bonner and Lloyd, 2011) has identified the body as a central source of information which is inscribed as vocabulary on the body, and made available to others who recognize its authority. Schatzki locates the body within practice theory by noting that many practice theorists consider practice as an "embodied materially mediated arrays of human activity centrally organized around shared practical understandings" (Schatzki, 2001, p.11). Practices provide the context for the composition of the body, for example the fashioning of identity and the development of information practices and information skills in relation to the tools people use in the context of the everyday lived experiences. (Lloyd, 2010; Lloyd \& Olsson 2018).

\section{Methodology}

The methodology of the study, is informed by a practice perspective that acknowledges the nexus of practices (Schatzki, 2002) as the central feature of everyday life, including shaping the information environments, landscapes and practices which shape people's experiences of information. This perspective focuses how information practices are shaped and maintained, in the context of people's actions and interactions with other people, materials, signs, symbols and tools which are all constituent elements responsible for the formation of information environments and information landscapes (Figure 1).

\section{Information Environments}

Over time, the car restoration hobby has created an established and stable information environment (Lloyd \& Olsson, 2018). This environment is represented through discourses which reference the modalities of information used by people. These have been described by Lloyd (2006) as the epistemic/instrumental modality where people engage with information sources that define the rules and structures of practice; the social modality referencing the tacit and nuanced expressions of social interactions and relations (histories); and the corporeal modality, representing embodied or contingent information drawn from and learnt through the body as it practiced or engaged with 'doing'. From an ontological perspective, information environments reference what happens in practice.

\section{Information Landscapes}

Information landscapes (Lloyd 2010) differ from information environments, because they reference how a practice happens. In this respect they are oriented epistemologically. People construct their information landscapes through the lens of an information environment, and through interaction with their actual enterprises and performances as they connect with people, material objects and embodied performances of a specific setting (Lloyd, 2010) - i.e. as practice happens. Information landscapes are therefore in the first instance intersubjective 
constructions. However, they also reflect an individual's subjectivity and agency as it is discursively materialized and understood (Barad, 2007) i.e. as the individual engages with the performances of a practice or when a practice is contested. When entering and engaging with a community, such as a restoration community, new members learn to map the information sources that are necessary to their practice. They learn about the material, economic, political and historical resources that shape the site of the social (Schatzki, 2002, Lloyd, 2006, 2010) and the range of information practices that will facilitate access to social and embodied knowledges of the practice. As they learn about these social, embodied and epistemic sources, they construct their information landscapes and define paths, nodes and edges with reference to the larger information environment. Learning about which information practices enable access to knowledge is integral to the formation of information landscapes e.g. information sharing, observing others and their environments, being reflexive.

\section{Information practices}

Information practices have been explored and defined by several scholars in the information studies field. Savolainen (2008) views information practices as habitual and identifiable in everyday settings. According to this view information practices are defined as a "set of socially and culturally established ways to identify, seek use and share the information available in various sources such as televisions, newspapers, and the Internet" (2008, p.2). The concept has also been notably explored by McKenzie (2003) focusing on how cognitive authority is constructed in discourse. Talja and Hansen's (2005) exploration of information sharing indicated that information practices are inherent within all social practices referencing community, sociotechnical infrastructures and language.

In the current study, information practices are treated as referencing the 'social' and therefore emerging socially and corporeally as in-situ ways of knowing. Lloyd defines information practices as:
An array of information-related activities and skills, constituted, justified and organized through the arrangements of a social site, and mediated socially and materially with the aim of producing shared understanding and mutual agreement about ways of knowing and recognizing how performance is enacted, enabled and constrained in collective situated action. (Lloyd, 2011, p. 285)

According to Schatzki (2002), practices are prefigured over time, being formed and reformed in relation to embodied knowledges. Information practices reflect this formation and reformation process, and consequently represent a dispersed practice which accommodates and reacts to the changing dynamics of a social site.

Lloyd has developed her understanding of information practices from studies of nurses, ambulance officers, firefighters and refugees and from other studies (e.g. Prigoda \& McKenzie 2007; Veinot, 2007; Savolainen, 2008) and argues that "information practices are 
context specific, and entwined with a range of modalities (social, corporeal and epistemic/instrumental) through which information work and performances of a specific setting are referenced" (Olsson \& Lloyd 2017, np.). This leads to the conclusion that embodied information practices

- $\quad$ are always situated (in situ);

- are expressed corporeally, and are central to actors understanding the social and epistemic modalities of the landscape;

- act as a site for know-how knowledge, which cannot be effectively expressed in written form (e.g. learning how to recognise an artefact; learning how to write; learning how read a fire);

- are local/nuanced, drawing from expertise in situ, and may be contingent and only available at the 'moment of practice'. (Lloyd \& Olsson, 2017)

In the study reported here, the project (car restoration) provides the central situational context and shapes the information practices of participants as they connect to the knowledges, practices and discourses which guide restoration. As Gherardi suggests;

Knowledge is not what resides in a person's head or in books or in data banks. To know is to be capable of participating with the requisite knowledge competence in the complex web of relationship among people material artefacts and activities...On this definition, it follows that knowing in practice is always a practical accomplishment (Gherardi, 2008, p. 517).

Collaboration between the two researchers was an important feature of this study, bringing an insider and outsider perspective to bear on the analysis of the community and its contexts. One researcher (Olsson) is a classic car owner and a second-generation car enthusiast, having grown up in the classic car scene. This insider status brought multiple advantages including facilitating recruitment, building rapport and establishing cognitive authority with participants, as well as the ability to understand the language, history and assumed knowledge inherent in participants' accounts of their practices. However, whilst insider status can bring many advantages, it also has its perils, in terms of a potential lack of critical distance (Bryman, 2008). The other researcher (Lloyd) was unfamiliar with the community at the beginning of the project and therefore in a strong position to provide critical insight into the often taken for granted elements of the remaking practice and community.

\section{Method}

At the time of writing, the study includes 15 participants, 13 from Australasia and two from the UK. Participant recruitment methods included the researcher's personal network (3 participants), car club meetings and newsletters ( 7 participants), volunteers at a motoring museum (2 participants), as well as snowball sampling (3 participants). Demographically, 14 of the participants were aged 55 or older, and there were 13 male and two female participants. The age and gender imbalance appear to fairly reflect participation in the hobby. Participants chose their own pseudonyms as an ice-breaking exercise, using a list of names of famous former racing car drivers provided by the researcher, although some negotiated similar names not appearing on the list,. 
Our analysis foregrounds men as the narrators of the project, and this narration is tied to identity, expertise, know-how and community. In interviews where wives were present, they are backgrounded and relegated by male participants to roles best described by us as documenters and archivists of restoration projects. This is not to say they are not 'present' within the project, merely that they are not constructed as central to its execution. The authors are aware of the limitations of a gendered study, but also acknowledge that the context of the study (car restoration) is demographically male oriented, however there will be attempts in further studies to explore this aspect.

The study's fieldwork adopted an ethnographic approach (Bryman, 2008) incorporating both in-depth semi-structured interviews and in the garage ethnographic observation of participants working on their current restoration projects. All fieldwork was carried out by Olsson using an interview guide and related materials designed by both researchers. The interview guide included some elements inspired by Dervin's Sense-Making methodology (Dervin et al., 2003), although the overall approach was also heavily influenced by Seidman's (1991) less structured, more conversational approach to research interviewing. Interviews lasted from 45 to 240 minutes and were digitally recorded. The researcher also observed eight of the participants during several hours working on their cars.

As was perhaps inevitable given the nature and context of the fieldwork and the researchers' interest in hands-on practices, the division between interviewing and observation was not clear cut. Since ten interviews took place in the participants' garages/workshops, it was quite natural for them to stop in the midst of the interview and show the researcher the relevant part of the car or demonstrate the technique they were describing. Similarly, there were occasions during the observation when participants would spontaneously break off from a task in order to either provide the researcher with a longer explanation of the task they were undertaking or to share a thought which had occurred to them. Far from being a limitation, the authors feel that this blended approach greatly enhanced the research experience for both participants and researchers, providing many insights that a more orthodox approach would have missed.

Analysis was undertaken using an inductive, thematic approach. Although the analysis was consciously informed by the range of theoretical perspectives described above, the study's aim was not to test a pre-defined theory or hypothesis, but rather to develop a contextual, situated understanding of the relationship between participants' context, their physical environment, their role/s as members of the classic car community, the discourses they engaged with and their information practices. In order to maximise the benefits of the insider-outsider approach, each researcher undertook their own initial thematic analysis before coming together to develop findings drawing on both researchers' insights and expertise. The analysis that ensues therefore conceptualises information practices as narrated from a male-oriented perspective, and considers how technology is implicated in both social and material practices associated with the car restoration.

\section{Findings}

Our analysis of participants' accounts and observation of them working on their restoration projects has shown that information environments and the landscapes which emerge are rich and complex. Whilst participants were certainly not ignorant of the opportunities that online resources and communities could afford them, these were largely seen as secondary, supplementing the more traditional resources and social networks that participants had developed, often over many decades, highlighting the importance of the lived experience to narratives of remaking. 


\section{Restoration as a multi-discursive space}

The study's findings demonstrate that participants' restorations occur in a discursive space where a range of competing discourses around what constitutes 'correct' practice exist. In this, there are clear parallels with Olsson's study of theatre professionals (2010) where participants' sense-making of Shakespeare drew simultaneously on both originality and creativity discourses.

Participants' accounts make it clear that in the context of classic car restoration there are multiple ways to engage with the concept of originality, with participants drawing on a range of different originality discourses to describe and justify their practices. For example, the 'factory original' approach sees a person seeking to restore their car to be as close as possible to the way it was when it first left the factory. A variant on this is to restore a car to the way it was at a particular point in its life e.g. when in competed at a famous race.

\section{I'm taking it back to how it looked at the 1935 Australian Grand Prix. (Straight)}

However, participants' accounts also drew on a range of other discourses that justify a range of more creative approaches. One of these is a 'perfection' discourse, where the restorer aims for a standard of craftsmanship far higher than was possible/feasible when the car was new, making the finished restoration a kind of Platonic ideal:

I want to make it as perfect as I possibly can - the factory could never afford to put this much time and effort into it! (Surtees)

Sometimes this is externally motivated, where the aim of the restoration is to produce a concourse/show standard car, but equally it can be more personal, with the restorer using the car to represent the embodiment of their own skills.

Other participants, some of them openly contemptuous of the 'concourse queen' (i.e. aimed at winning prizes at car shows) school of restoration, adopt a 'fit for purpose' approach, arguing that the selective application of more modern technology, such as brake upgrades or electronic ignition, which make the car safer, more reliable or enhance the driving experience, are entirely appropriate. Three participants drew on the long history of building 'specials' in motorsport and hot-rodding to create one-off vehicles, using period components, inspired by cars from the 1930s-50s but ultimately their own creations.

\section{Learning by doing}

One of the first things to strike an outside observer of car restoration is the complexity of the challenges involved, the breadth of skills and knowledge it requires, and the time commitment, which often runs into thousands of hours over a period of years.

This car is one of three and the only one in the country. It took me about four years to restore. I got the chassis at an estate auction in rural Victoria... I chased up the nephew of the guy and got onto a shed on another family property where I dug up an engine and a few other bits and pieces from under about 50 years of old junk! The rest is about finding what you can and then making what you can't. (Straight)

A striking feature of participants' accounts of their restoration practices was the relish with which they described the seemingly insurmountable problems and challenges their projects 
had thrown up and the various strategies and skills they applied to overcoming them. Many participants described the difficulty of restoration not as a barrier but one of its principal attractions for them:

I know lots of people think I'm mad - including my wife! - but I love taking on these basket cases. I love the challenge. (Chiron)

One participant even advertised in his car club newsletter for difficult restorations, including 'before' and 'after' photos of his two most recent restoration projects showing how he had transformed them from piles of rusting scrap metal to shining perfection. Participants' accounts manifest their strong feelings of pride and accomplishment in being able to bring their project cars back from the dead. In a sense, their cars can be seen as the embodiment of their skills, as well as tangible evidence of a concrete achievement.

Twelve participants described a love of practical challenges and working with their hands as having been part of their lives from childhood:

I was always a hands-on kind of bloke, even as a kid l'd be building things or fixing things (Moss)

This theme of independence, an ability to solve complex practical problems and learning by doing, was a powerful discourse throughout the research, with all participants emphasising that most of their skills and knowledge around car restoration had been acquired experientially:

I just picked it up over the years: engines, gearboxes. ... a fair bit of trial and error. I now feel that if I don't know how to do it, I've got enough experience I can probably work it out. (Moss)

For most participants, this idea of being a fixer and maker seemed to play a central role in their construction of their own identity. Underlying their accounts was a discourse of masculinity in which male identity is defined by an ability to solve practical problems in a hands-on way.

\section{Corporeal learning in embodied information practices}

Participants' descriptions of the challenges of car restorations naturally included discussion of the dearth of documentation, particularly in relation to vintage cars:

Restoring a vintage Delage isn't like working on a modern car or even restoring something like a Mini or an MGB [mass-production models from the 1960s]. They're hand-made and everyone is different. There's no owner's manual and if there ever were factory build sheets, they're long gone. (Davison)

However, even where owners and workshop manuals existed, and where they were acknowledged as an invaluable resource, participants recognised that there were limits to what one could learn from a printed resource: 
Even if you've got a manual, it can only take you so far. When you start doing it, there's lots of things a book can't tell you. (Hulme)

Both interviews and observation indicated that the acquisition and use of information was inextricably linked to embodied practices. As in Olsson's (2016) study of archaeologists in the field, when participants described working on their cars, they frequently used tactile language to describe what they were doing:

You've really got to develop a feel for the metal as you're shaping it ... Aluminium reacts very different to steel. (Clark)

Significantly, throughout the interviews and whilst they were being observed working on their cars, participants used dialogic language to describe their relationship with the car/part they were working on:

She doesn't like that. I'll have to try something else. (Aston)

When I'm making a panel, the feel I get from the metal tells me how much pressure to apply. (Clark)

Both their descriptions and the researcher's observations support a Latourian interpretation of the relationship between the participants, the tools they use and the cars they are working on i.e. that both people and objects are actors in the practice of car restoration (Latour, 2005). The physical properties of the objects afford certain 'correct' ways of use, and in doing so shape the participants' sense-making, and the decisions they make in solving the problems their restoration projects throw up.

\section{Use of online resources and communities}

All participants described the internet as a resource for them in their restoration projects. However, although many participants were enthusiastic about how the web had made restoration easier, for the majority the only online practices they described were using search engines and sales sites like eBay as a means to find and purchase car parts:

The great thing is that you can jump online and find what you're looking for. You can get parts in from the US or England. (Hulme)

Multimedia resources were little used by the study's participants, although one of the younger participants, albeit in his mid-fifties, did describe making use of online video in the context of one part of his restoration practice:

\section{For the English wheel, there's a lot of really good stuff on YouTube ... You can watch some of the top guys in the UK or wherever .... (Clark)}

This participant, who was highly skilled at fabricating body panels from scratch, used YouTube as a learning tool to improve his practice using the English wheel, a metalworking tool that enables a craftsperson to form compound (double curvature) curves from flat sheets of metal such as aluminium or steel (Smith, 2015). He was very purposeful in his use of YouTube, undertaking detailed searches to the specific technique or task he was undertaking at the time rather than subscribing to any channels. 
Although there are numerous online forums, Facebook pages etc. devoted to car restoration, only three of the study's participants described regularly engaging with these online communities. All participants were aware of them and most had some experience of using them, but even those who were active users were hesitant in their use of digital resources, and talked about them as problematic sources of information:

\section{There are a lot of so-called experts [online] and a lot of them don't know what they're talking about! (Straight)}

Many talked about the problem of assessing the authority and expertise of online advice:

Someone can tell you to do it one way but you have to ask yourself "Have they actually done it themselves? Or is it just something they've heard or read about?" (Clark)

Participants' accounts thus make it clear that one of the principal reasons they find judging the authority of online advice is not just not knowing the person giving the advice but, more importantly, not being able to see their restoration work and therefore not being able to assess their levels of embodied expertise.

\section{Non-use of online resources and communities}

It would be tempting to ascribe the relative lack of use of online information resources and communities to insufficient experience or skill, or even to technophobia - all tropes that appear frequently in discussions of the information behaviour of older people. To do so in the context of the present study, however, would be to greatly underestimate the participants' abilities and judgement. Half the participants were university educated, many held senior positions in the working lives and all did make some use of online resources to support their project, but more so in their everyday lives. Furthermore, their success in carrying out their restoration projects, and the respect their peers had for them, requires us to take seriously the participants' own explanations for their non-use: that online resources were less effective than the practices they did employ:

\section{I've had a look at them [online forums] now and then but really you can end up wasting a lot of time with idiots! (Straight)}

We would argue that participants' critical stance in relation to online resources needs to be understood in the context of the study's finding that car restoration is a multi-sensory embodied practice.

Look, working on these cars is very hands on. Drawings, even a video only get you so far. That's why the best way to learn - really the only way - is hands-on. (Aston)

It is possible that the lack of use of online resources may be attributable to other characteristics of the study's participants, which might make their practices not representative of the broader car restoration community. All but one of the participants were highly experienced car restorers, and were regarded by other members of the community as being particularly skilled. This may be an unintended consequence of the study's recruitment methods in that both Olsson's personal connections in the community, and car club committee members he asked for recommendations, were likely to nominate the most expert restorers they knew. Equally, it is possible that more skilled restorers were more likely to respond to the researchers' call for volunteers made at car club meetings and through club newsletters. 
Without doubt, the main reason for non-use was participants' extensive personal network of expert fellow restorers (described in the next section):

I don't need to ask someone I don't know on the internet... What I really like about the club is that there are people there, like Moss, who've been restoring these cars for years. Between them, they know everything there is to know about Bristols. (Webber)

Another factor may be that 12 of the 15 participants lived in their state's capital city:

That's one of the advantages of living in Melbourne. The car companies were all based here and so are the people with the expertise. (Edsel)

It may therefore be the case that those with lower levels of expertise, and/or less access to an expert community of peers where they live, may make greater use of online resources to support their restoration practices. This is something that the next stage of the study will seek to address.

\section{"I know a bloke" - networks of practice}

Common to all participants' accounts was the central importance of their relationships with their fellow car enthusiasts. As described by both male and female participants, car restoration is a social world largely made up of (mostly older) men. For all participants, the social relationships developed with other enthusiast restorers provided active mentoring at the beginning of their involvement in the hobby, and continued to support their restoration projects today. Significantly, the support that participants described was not only technical or material but also emotional. Perhaps the most striking feature of participants' accounts was how feelingly they discussed the importance of working on their cars as a source of satisfaction and a source of emotional support during difficult times in their lives.

For 11 participants, their involvement with classic cars began in childhood or their early teens and involved mentoring by an older man. For some this was a relative:

Dad was a panel-beater [body fabricator] and he taught me a lot from a young age. (Clark)

For others, it was a family or a school friend. The research also included examples of participants themselves carrying on this form of cross-generational mentoring:

It's become a family thing. My sons grew up working on the cars with me. The other day some of my grandkids were over and I was showing my grandson how to do a few things - standing on a chair to reach the bench! (Surtees)

For the most part, the relationships described were markedly gendered, with both mentor and student being male. However, the research was very fortunate to include one exception to this. One participant, Cobb, a teenage girl of Asian heritage, volunteered at a major transport museum as part of as part of a youth development scheme, and was mentored by Barnato:

I was working on the Napier so told her a little bit about it and said she could polish the body and talk to visitors while I was working under the car. I then heard her telling 
visitors everything I'd told her - except in chronological order and in better English! (Barnato)

I think I impressed him and he's started teaching me how to do things -check the tyre pressures, measure how much fuel is in the tank. (Cobb)

Many participants continued to learn key skills through informal mentoring relationships into adulthood:

There was an older guy, an aircraft engineer, I hung around and got some advice from him. (Moss)

These relationships appear to have much in common with the master-apprentice relationships described by Lave and Wenger (1991). However, even the most experienced and expert participants emphasised the importance of their network of fellow enthusiast restorers in supporting their current projects. Car clubs played an important role in facilitating these networks:

A group of us who were more interested in restoration than the social side formed the MG Restorers Club. We get together every month to talk about our projects and one person gives a presentation on their car. (Surtees)

However, 13 participants emphasised the importance of contacts they had developed more informally, even serendipitously:

I had this car out on the driveway and this guy was walking past and stopped to chat. He was interested, and it turned out he was a retired Qantas engineer. After that, he'd stop by and lend a hand. ... I'd never have been able to sort out the wiring harness without him. (Webber)

These networks of social knowledge sharing were often based on relationships spanning decades:

I had this mate from school who was into cars. We started working on them when we were 15 and we still get together and talk about cars and we still help each other out. (Straight)

Focus on men talking about solidarity: Embodied practice, achievement and identity Participants' accounts, however, made it clear that their social networks were not only a source of expertise or material assistance, but were also an essential source of emotional support:

The club was like a touch-base sanity for me ... you can't do it on your own. (Webber)

Issues of social isolation and inability to express their emotions amongst men has long been of concern in western society. The study's findings suggest that the male participants in the study found both social connection and emotional support through the friendships their involvement in car restoration afforded. 
Furthermore, all participants talked in explicitly affective ways about the satisfaction that working on their cars gave them; a satisfaction that was frequently missing in other parts of their lives:

These days you don't feel like you're achieving anything at work. I trained as an engineer but now I'm in charge, I do admin, not engineering. When I'm working on the car, I can see that I'm doing something! (Clark)

For participants, the restoration process therefore had a clear affective element, with their cars becoming an embodiment of a positive construction of the self. It may well be that this is particularly important for older, retired men who no longer have a work role around which to construct their sense of identity.

I've really got into taking on restoration projects a lot more since I retired.... It gives me a reason to get up in the morning. (Aston)

Participants also described the important role that working on their cars played in helping them deal with stressful events in their lives:

[My wife] has been battling cancer for the past few years and I've been looking after her ... mucking about with these old cars has kept me sane! (Webber)

Whenever I've had stresses or problems in my business or family, I've come out here [to the garage] and worked on the cars. (Moss)

Participants' accounts make clear that in developing and sharing the information practices needed for car restoration, they are not only acquiring new knowledge nor is their aim purely functionalist. Rather, as well as reconstructing their classic cars, the participants are also reconstructing their own identity as skilled member of a community of like-minded peers. The participants themselves suggest that this is particularly important for those who are retired and no longer have their careers as a source of social identity and status. Theories around identity work in critical discourse analysis (Ainsworth \& Hardy, 2004) and organization studies (Alvesson et. al., 2008) have thus far had relatively little impact in information practices research but the present study suggests not only that they may be a useful tool for future research but that they might usefully be applied in leisure as well as work-related contexts.

\section{Discussion: Untangling the knot of information practices}

Our attempt to untangle the knot of information practices and ways of knowing that scaffold the larger practice of restoration, reveals that information practices are not only connected to normative knowledges associated with the restoration of vintage and classic cars, but are also intricately tied to embodied knowledge derived from lived experience, social knowledges around community membership, and through ( in this study) the gendered narratives of solidarity which bind this male dominated community of practice (Gherardi, 2008; Wenger,1998). The interview responses characterise the information landscapes of car enthusiasts as being composed of epistemic/instrumental, physical, and social information modalities which entwine to shape the discursive practices of restoration. Becoming a car restorer involves engaging with the broader discourse and practice community of restoration, but is also framed to a specific type of car being restored, thus shaping an understanding of how restoration happens and how the restoration community operates. 
Coming into the practice of restoration, becoming part of a restoration community, and connecting with information environments which shape the normative discourses of restoration practice, is scaffolded by access to these information modalities which hang together (Schatzki, 1996) to create an intersubjective space, which bounds the practice of restoration and its projects (remaking classic cars) and arrangements. Engaging in the intersubjective space, allows people to engage with shared histories and the rules of the community, and in turn develop shared understandings which contribute to the shaping of restoration identity (often further refined according the type of car being restored). Central to this idea is Barad's conception that "knowledge is always a view from somewhere" $(1996, \mathrm{p}$. 179) and we would suggest that information practices reflect and reference the arrangements of a social site and the ways of knowing that are legitimized and valued within practice (Lave and Wenger, 1999; Lloyd, 2010; Orlikowski \& Scott, 2015).

Opportunities for interaction with the social, epistemic/instrumental, and corporal modalities occur because, in the first instance, the car creates technical and social information needs: i.e. How do I remake, how do I find this part, how do I make this part, what does this part consist of, who do I know that can provide me with information, what social and expertise networks are available to me to help me operationalize the process of remaking? In the second instance, the car furnishes opportunities that meet complex social needs (how do I meet people with expertise, learn to speak the language of restoration, connect with the stories of restoration, and locate my community and physical opportunities to access information (why does this not work, how do I make this, is there a trick to getting this to fit?) that is only available at the moment of practice and draws from expertise that resides in the body. Therefore, the car becomes the focus of participants' need to access information on technical, social, and emotional levels and this information is only picked up because the participants are involved in the practice of restoration.

The analysis suggests that information practices such as observation and reflection on practice (learning by doing), were privileged and valued because they enabled participants' access to the embodied knowledge of others and to nuanced ways of knowing that were not available to them in documented form. The construction of information landscapes therefore references the mapping of specific nuanced and embodied ways of knowing which are established over time and reflect long developed expertise and performative knowledges (Orlikowski \& Scott, 2015).

The findings also draw attention to the role of the body and learning to interpret corporeal information from different senses which is critical for problem solving the challenges which come from restoring classic vehicles. Approaches to problems often depend on access to an array of corporeal and social information sources and the need to develop strategies to pool together knowledge and expertise to create work arounds for mechanical problems where expertise and explicit knowledge may be lost or not documented. This aspect has emerged in earlier research by Lloyd (2009) and Olsson (2016) and more recently in studies related to diabetes (Jean, Jindal, and Ghan, 2018) and cardiopulmonary resuscitation by bystanders (Lindh, 2018) thus highlighting the need to ensure that exploration of information practices is not limited or reduced to cognitive elements, but considers the role of the corporeal modality in the construction of practice. In this respect, the body is viewed as performing signifying and instrumental roles (who is an expert), revealing the nature of the site, in terms of what knowledges are valued and forms of practical reasoning. In describing the body in practice 
Schatzki, 1996) suggests that "it is through the performance of bodily actions that the performance of other actions is constituted or effected" (Schatzki, 1996, p. 44).

The present study demonstrates how information practices are shaped by bodies to accommodate learning that is experiential and often difficult to articulate because it is sensory, sentient, and reflexive and drawn from experience accumulated over time often through trial and error. Bodies and the information they possess, produce, and disseminate (Lloyd 2010) are central for understanding how practices happen. This point is made by Gherardi (2009) who highlights the relationship between knowledge and practice by stating that "not only do people work with their bodies, but they also know through them" (p. 354).

The study's findings indicate that we should also consider the materiality of practice by paying attention not only to bodies, but to objects made and manipulated by them, in particular the potential of tools and other objects, such as sheet metal and car parts, and the cars themselves to be entangled in practice, in ways that shape practical and symbolic understanding (Reckwitz, 2002; 202; Latour 2005; Schatzki 2002). In a previous study of field archaeologists Olsson (2016), noted that participants' accounts and observation of their practice demonstrate that it is their active multi-sensory engagement with these objects in the moment of practice that allow them to gain an understanding of both the object itself and how to work with it in completing a piece of work. This suggests that a practice perspective, such as the study employs, offers information researchers the possibility to expand their thinking about the information affordances of objects that have not been previously considered as objects for research attention.

In the present study, the non-digital world was privileged by car enthusiasts and accorded value as a significant site of knowledge and source of information. Less emphasis was placed on social media platforms or information technology, which became backgrounded in favour of the social and corporeal sources of embodied knowledge which were derived from practical and performative understandings (Gherardi, 2008; Orlikowski and Feldman, 2011). The non- digital aspects of the restoration practice influenced the shape and conduct of information practices in situational and relational ways and across spatial and temporal boundaries i.e. connecting with other people with shared interests/histories of restoration developed over time, observing restoration practices to learn about tricks of the trade, and the sharing of information and experiences (Reckwitz, 2002). The opportunities furnished by the social space create the conditions for intersubjectivity, which evolves from sharing and developing a joint understanding of what happens in practice as it unfolds in everyday life. More importantly to the men in this study, it appears the social contact (through social networks) and discourse created contribute to identity and provides emotional support.

Recent research (Huvilla 2018) has canvassed the entwinement of technology and its role in setting standards for social conduct, proposing the relationship be viewed as one of accommodation rather than one of resistance. However, this assertion comes into question in the present study of restoration, where the uptake of opportunities offered by digital technology and its contribution to social conduct, appear more limited and less accommodating than the researchers had initially assumed. While use of digital technology and social media platforms were discussed and there was an awareness and use of platforms such as Facebook and You Tube, participants reported this use as secondary and accorded it a limited role in supporting their restoration practice. We propose this may be because of the participants need to observe the work of other enthusiasts (and to sometimes participate in that work), to recognise responses or cues that can only occur at the moment of practice 
(Bonner \& Lloyd, 2011). Earlier research with ambulance officers and nurses (Lloyd 2009; Bonner and Lloyd, 2011) described how both groups preferred to watch a person as they executed procedures and then practise and discuss the performance because it was more relatable and 'in the moment' than reading about it.

In adopting an information perspective that is influenced by practice theory, our approach has been to treat information practices as social and dialogical articulations which reference situated and the relational elements of the social site (Lloyd, 2010; Talja; 2005). This allows us to view information practices as simultaneously inward and outward facing. Inward facing elements of practice referencing the embodied and nuanced ways of knowing which are critical to developing an intersubjective position in relation to the membership of a group or community of practice (Lave and Wenger, 1999; Wenger, 1998; Schatzki, 2002; Mahon et, al, 2017). Outward facing elements of the practice reference the epistemic knowledges that are important to enthusiasts (e.g. documents, manuals, catalogues). We consider this approach to be a useful way of expressing how information practices happen and support the concept of practice as having spatial and temporal orientations (Reckwitz, 2002; Schatzki, 2005) which influence the arrangements of the social site. As Savolainen (2009, np) suggests "knowledge and knowing should not be competing but complementary and mutually enabling".

\section{Conclusion}

The present study offers an example of how an information practices perspective can afford information researchers a richer construction of the contexts and communities they engage with. Whilst information research has long moved beyond a narrow focus on informational artefacts (books, databases etc.), we have continued to focus our research attention almost exclusively on forms of information practice based on linguistic or symbolic representation. Non-linguistic practices where symbolic representation is problematic have traditionally posed a problem that prevailing approaches have lacked the theoretical and/or methodological tools to deal with effectively.

The study has been able to demonstrate that enthusiast car restorers form a community where, embodied information practices are shared structured social constructs that defy being classified as 'tacit knowledge'(Nonaka, \& Takeuchi, 1995). For participants in this study, the project of the car does not simply represent the remaking of a physical object. It is also intrinsically tied to complex knowledges and narratives that surround discourses of expertise, embodiment and solidarity. Significant to this analysis is the emotional affordance furnished by the project, and its contribution to identity formation. The findings indicate that the practices are significant because they reveal that participants are engaged in much more than applied problem solving. Rather, they suggest that, for most participants, their engagement in the social world of car restoration and the networks of social knowledge sharing it affords is significant for the emotional support it provides in an epistemic context where, for older men, such opportunities are limited. In a sense, the participants are not only rebuilding their cars but also their own sense of self, in a world where they may feel that traditional notions of masculine identity are questioned. We believe that the relationship between information practices and identity construction is a central one for our field, one that narrower approaches focused on individual information seeking are not equipped to address. 


\section{References}

Ainsworth, S. \& Hardy, C. (2004). Critical discourse analysis and identity: why bother? Critical Discourse Studies, 1 (2), 225-59.

Alvesson, M., Ashcraft, K.L. \& Thomas, R. (2008). Identity Matters: Reflections on the Construction of Identity Scholarship in Organization Studies. Organization, 15, (1), 5-28.

Barad, K. (2007). Meeting the universe halfway: Quantum physics and the entanglement of matter and meaning. Durhman, NC: Duke University Press.

Bonner, A., \& Lloyd, A. (2011). What information counts at the moment of practice? Information practices of renal nurses. Journal of Advanced Nursing, 67(6), 1213-1221.

Bourdieu, P. (1977). Outline of a Theory of Practice. Cambridge University Press, Cambridge, United Kingdom.

Bourdieu, P. \& Wacquant, L. (1992). An Invitation to Reflexive Sociology. Polity Press, Cambridge, UK.

Bryman, A. (2008). Social research methods (4th ed.). Oxford: Oxford University Press.

Case, D.O. (2009). Serial collecting as leisure, and coin collecting in particular. Library Trends, 57 (4), 729-752.

Cox, A.M., Griffin, B. \& Hartel, J. (2017). What everybody knows: embodied information in serious leisure. Journal of Documentation, 73 (3), 386-406.

DeLyser, D., \& Greenstein, P. (2017). The Devotions of Restoration: Materiality, Enthusiasm, and Making Three "Indian Motorcycles" Like New. Annals of the American Association of Geographers, 107(6), 1461-1478.

Dervin, B., Foreman-Wernet, L. \& Lauterbach, E. (2003). Sense-Making methodology reader: selected writings of Brenda Dervin. Cresskill, NJ: Hampton Press.

Dourish, P. (2001). Where the action is: the foundations of embodied interaction. MIT press.

Feldman, M. S., \& Orlikowski, W. J. (2011). Theorizing practice and practicing theory. Organization science, 22(5), 1240-1253.

Fulton, C. (2009). Quid pro quo: information sharing in leisure activities. Library Trends, 57 (4), 753-768.

Giddens, A. (1984), Constitution of Society: Outline of a Theory of Structuration, Polity Press, Cambridge.

Gherardi, S. (2009). Introduction: the critical power of the 'practice lens'. Management Learning, 40(2), 115-128. 
Gherardi, S. (2008). Situated knowledge and situated action: what do practice-based studies promise? In D. Barry and H. Hansen (Eds.), The Sage handbook of new approaches in management and organization (pp. 516-527). Thousand Oaks, CA: Sage Publications Ltd.

Gherardi, S., \& Nicolini, D. (2000). The organizational learning of safety in communities of practice. Journal of management Inquiry, 9(1), 7-18.

Gorichanaz, T. (2015), Information on the run: experiencing information during an ultramarathon. Information Research, Vol. 20 No. 4.

Hartel, J. (2006). Information activities and resources in an episode of gourmet cooking. Information Research, 12 (1), paper 281. Retrieved 10 March 2018 from http://informationr.net/ir/12-1/paper282.html

Heley, J. \& Jones, L. (2013). Growing older and social sustainability: considering the 'serious leisure' practices of the over 60 s in rural communities. Social \& Cultural Geography, 14(3), 276-299.

Hickman, M. Stokes, P. Beard, C. \& Inkster, A. (2017). Doing the plastic fantastic: 'artificial' adventure and older adult climbers. Journal of Adventure Education and Outdoor Learning. DOI: $\underline{10.1080 / 14729679.2017 .1308874}$

Houston L. (2017). The Timeliness of Repair. Continent 6 (1), 51-55.

Huvila, I. (2018). Putting to (information) work: A Stengersian perspective on how information technologies and people influence information practices. The Information Society 34 (4), 229-243.

Jackson, S.R. (2014) Rethinking Repair. In T. Gillespie, P.J. Boczkowski, and K.A. Foot (Eds.) Media Technologies: Essays on Communication, Materiality, and Society (pp 221-239). MIT Press.

Jean, B. S., Jindal, G., \& Chan, K. (2018). "You Have to Know Your Body!” The Role of the Body in Influencing the Information Behaviors of People with Type 2 Diabetes. Library Trends, 66(3), 289-314.

Joseph, P. (2016). Australian motor sport enthusiasts' leisure information behaviour. Journal of Documentation, 72 (6), 1078-1113.

Kemmis, S., \& Grootenboer, P. (2008). Situating praxis in practice: Practice architectures and the cultural, social and material conditions for practice. In Enabling praxis: Challenges for Education, S. Kemmis and Smith , T.J ( Eds,). pp. 37-62. Sense: Rotterdam

Latour, B. (2005). Reassembling the social: an introduction to actor-network-theory. Oxford New York: Oxford University Press.

Lave, J. \& Wenger, E. (1991). Situated learning: legitimate peripheral participation. Cambridge: Cambridge University Press. 
Lindh, K. (2018). The Construction of Lay Rescuers in Bystander CPR Classes, Library Trends, 66(3), 315-328.

Lloyd, A. (2009). Informing practice: information experiences of ambulance officers in training and on-road practice. Journal of Documentation, 65(3), 396-419.

Lloyd, A. (2010). Framing information literacy as information practice: site ontology and practice theory. Journal of Documentation, 66(2), 245-258.

Lloyd, A. (2011). Trapped between a rock and hard place: What counts as information literacy in the workplace and how is it conceptualized. Library Trends, 60(2), 277-296

Lloyd, A. (2014). Informed bodies: Does the corporeal experience matter to information literacy practice? In Information experience: Approaches to theory and practice (pp. 85-99). Emerald Group Publishing Limited.

Lloyd, A. (2017). Information literacy and literacies of information: a mid-range theory and model. Journal of Information Literacy, 11(1).

Lloyd, A \& Olsson, M (2018 in press) Enacting and capturing embodied knowledge in the practices of car restorers, Journal of Librarianship and Information Science.

McKenzie, P (2003). A model of Information Practices in Accounts of Everyday Life Information Seeking. Journal of Documentation, 59, (1), 19-40

Mahon, K., Kemmis, S., Francisco, S., \& Lloyd, A. (2017). Introduction: Practice theory and the theory of practice architectures. In Exploring Education and Professional Practice (pp. 1-30). Springer, Singapore.

Nicolini, D. (2012). Practice theory, work, and organization: An introduction. Oxford University press.

Nonaka, I. \& Takeuchi, H. (1995). The knowledge creating company: how Japanese companies create the dynamics of innovation, New York: Oxford University Press.

Olsson, M. (2009), Re-Thinking our Concept of Users, Australian Academic \& Research Libraries, vol. 40, (1), 22-35.

Olsson, M.R. (2010). All the world's a stage - the information practices and sensemaking of theatre professionals. Libri, 60 (3), 241-252.

Olsson, M. (2016). Making sense of the past: the embodied information practices of field archaeologists. Journal of Information Science, 42(3), 410-419.

Olsson, M. \& Lloyd, A. (2017). Being in place: embodied information practices. Information Research 22(1). Retrieved March 28, 2018 from http://InformationR.net/ir/22$\underline{\text { 1/colis/colis1601.html }}$ 
Olsson, M. \& Lloyd, A. 2017, 'Losing the art and craft of know-how: capturing vanishing embodied knowledge in the 21st century', Information Research 22(4). Retrieved March 28, 2018 from http://www.informationr.net/ir/22-4/rails/rails1617.html

Orlikowski, W. J., \& Scott, S. V. (2015). Exploring material-discursive practices. Journal of management studies, 52(5), 697-705.

Pilerot, O. (2013). A practice theoretical exploration of information sharing and trust in a dispersed community of design scholars. Information Research: An International Electronic Journal, 18(4), n4.

Prigoda, E. \& McKenzie, P. (2007). Purls of wisdom: a collectivist study of human information behaviour in a public library knitting group. Journal of Documentation, 63(1), 90114.

Reckwitz, A. (2002). Toward a theory of social practices: A development in culturalist theorizing. European journal of social theory, 5(2), 243-263.

Savolainen, R. (2007). Information behaviour and information practice: reviewing the 'umbrella concepts' of information seeking studies. Library Quarterly, 22(2), 109-132.

Savolainen, R. (2008). Everyday information practices: a social phenomenological perspective. Lanham, Md.: Scarecrow Press.

Schatzki, T. (1996). Social practices: a Wittgensteinian approach to human activity and the social. Cambridge, UK: Cambridge University Press.

Schatzki, T. R. (2002). The site of the social: A philosophical account of the constitution of social life and change. Penn State Press

Shilling, C. (2012). The body and social theory. Sage. Thousand Oaks.

Seidman, I. (1991). Interviewing as qualitative research: a guide for researchers in education and the social sciences. New York: Teachers College Press.

Smith, S. (2015,). How this medieval machine turns flat metal into beautiful car bodies. Road \& Track. Retrieved from http://www.roadandtrack.com/car-culture/classiccars/a26081/lost-art-the-english-wheel/ (Archived by WebCite\&reg; at http://www.webcitation.org/6nulvXPe7 )

Stebbins, R.A. (2007). Serious Leisure: A Perspective for Our Time. Transaction Publishers, New Brunswick, NJ.

Sundin, O., \& Johannisson, J. (2005). The instrumentality of information needs and relevance. In International Conference on Conceptions of Library and Information Sciences (pp. 107-118). Springer, Berlin, Heidelberg.

Talja, S. (2005). "The Domain Analytic Approach to Scholar's Information Practices." In [13], pp. 123-27. K. Fisher, S. Erdelez, and L.McKechnie, (Eds.), Theories of Information Behavior. (pp123-127). Medford, NJ: Information Today. 
Talja, S. Tuominen, K. \& Savolainen R. (2005). "Isms" in information science: constructivism, collectivism and constructionism. Journal of Documentation 61(1), 79-101.

Talja, S \& Hansen, P. (2005) Information Sharing, in New Directions in Human Behaviour, ed Spink, A \& C.Cole. Berlin:Springer, p113-34

Veinot, T. C. (2007). "The Eyes of the Power Company”: Workplace information practices of a vault inspector. Library Quarterly, 77(2), 157-179.

https://doi.org/10.1086/517842 